\title{
Association of Metastasis with Clinicopathological Data in Mexican Patients with Osteosarcoma, Giant Cell Tumor of Bone and Chondrosarcoma
}

\author{
E Estrada-Villaseor ${ }^{1}$, R Escamilla-Uribe ${ }^{2}, P_{\text {De la Garza-Montano }}^{2}$, R Dominguez- \\ Rubio $^{3}$, V Martinez-Lopez ${ }^{4}$, A Avila-Luna ${ }^{2}$, A Alfaro-Rodriguez ${ }^{2}$, EK Ruvalcaba- \\ Paredes $^{5}$, D Garciadiego-Cazares ${ }^{4}$, C Bandala ${ }^{2 *}$
}

\begin{abstract}
Background: Bone tumors are neoplasias with a high overall mortality; one of the main factors that reduce survival is their high capacity to develop metastases. It has been reported that finding lung metastases at diagnosis of osteosarcoma (OS), chondrosarcoma (CS) and giant cell tumor of bone (GCTb) is quite common. In this study, we inquire the relationship of metastases caused by these tumors with different clinical and pathological aspects, in order to guide medical personnel in the diagnosis and opportune treatment of metastases or micro metastases. Materials and Methods: We collected data of 384 patients with clinical, radiological and histopathological diagnosis of OS, GCTb and CS that attended the National Rehabilitation Institute (INR) during 2006 to 2014. Chi-square and Fisher's exact tests were performed for data analysis. Results: In the three tumor types, the presence of metastases at diagnosis was variable $(p=0.0001)$. Frequency of metastases was $36.7 \%, 31.7 \%$ and $13.2 \%$ for OS, CS and GCTb respectively. The average age had no significant difference $(p>0.05)$ in relation to metastases, even so, patients with OS and GCTb and metastases, were older while patients with CS and metastases were younger, in comparison to patients without metastases. Males had a higher frequency of metastases $(68.2 \%, p=$ 0.09 ) in contrast to $\mathrm{CS}$ and GCTb, in which the metastases was more frequent in women with $51.9 \%(p=0.44)$ and $57.9 \%(p=0.56)$ respectively. Broadly, metastasis was associated with primary tumors located in the femur (44.4\%), followed by the tibia (15.6\%); metastases was more frequent when primary tumor of GCTb and OS were in the same bones, but were located in the hip $(\mathbf{2 6 . 3 \%})$ for CS. Conclusions: The frequency of metastases in OS, GCTb and CS is high in our population and is determined by different clinicopathological variables related to the kind of tumor. Further studies are needed in order to evaluate metastases subsequent to diagnosis and associations with survival and clinicopathological factors , as well as to determine the sensitivity and specificity of current methods of detection.
\end{abstract}

Keywords: Giant cell tumor of bone - chondrosarcoma - osteosarcoma - metastasis.

Asian Pac J Cancer Prev, 16 (17), 7689-7694

\section{Introduction}

The National Institute of Rehabilitation (Mexico City) has reported that $\mathrm{OS}$ is the most frequent malignant bone tumor $(46.6 \%)$ followed by the CS $(8.7 \%)$ and the most frequent benign bone tumor was GCTb (14.6\%), this study were performed during the period of 2000-2005. (Baena-Ocampo et al., 2009; Uribe-Rosales et al., 2014). Different studies showed that the lung is the most common site of metastases in this kind of tumors.(Llamas-Duran et al., 2011; Yang et al., 2012; Choeyprasert W et al., 2014)

OS is the most common malignant primary bone tumor; predominantly affecting young people, comprising about $20 \%$ of primary bone sarcoma (Huang et al., 2015) of $11 \%$ to $20 \%$ of patients have detectable metastases at diagnosis, while the percentage of event-free survival at five years is approximately $60 \%$ to $70 \%$ in patients with localized disease. (Picci, 2007) Although control of the primary tumor can be achieved with the amputation of the affected limb, since seventies it is known that $80 \%$ to $90 \%$ of patients relapse with lung metastases at a median of five months after surgery without adjuvant treatment, reflecting that these patients have subclinical metastases or micrometastases at the time of diagnosis undetectable by standard techniques (Martinez-Cedillo, 2012). National Institute of Pediatrics (Mexico, City) performed an study about this, and they founded that OS had $31 \%$ of lung metastases at diagnosis; in other countries, they have been reported frequencies ranging from $30 \%$ to $45.7 \%$ (Zuniga et al., 2005; Yang et al., 2012; Choeyprasert et al., 2014). 


\section{E Estrada-Villaseñor et al}

CS displays a similar vascular distribution pattern to normal cartilage: large tumoral lobes surrounded by fibrous tissue septa containing small vessels. Intratumoral high vascular density is observed in some nonconventional CSs (mesenchymal and dedifferentiated) that present a low quantity of extracellular matrix and a high density of malignant cells. Indeed, cartilaginous tumors that present a low density of extracellular matrix (high-grade and nonconventional CSs) usually have high microvessels density, probably secondary to less inhibition of vessel formation (Cintra et al., 2014). Periosteal chondrosarcoma wide surgical resection is the recommended treatment. Prognosis is usually good if surgery is adequate. Metastasis is late and very rare. Metastasis happened especially in the spine, pelvis, bilateral femurs, and humerus in the absence of local recurrence at 10 months after operation (Liu et al., 2015).

$\mathrm{GCTb}$ is a rare bone tumor that constitutes $3 \%$ to $5 \%$ of bone neoplasms and is frequently found in metaepiphyseal region of long bones (Azarpira et al., 2015). GCTb is a primary intramedullary tumor which is supposedly benign but can be locally aggressive and even metastatic. Its name originated from the giant cells found within the tumor. It has the highest prevalence among the population aged between 20 and 40-years-old and has a slight female predominance. The most usual sites for GCTb include long bones (75\%-90\%) distal femur, proximal tibia and distal radius (Murphey et al., 2001; Turcotte, 2006; Raskin et al., 2013). The natural history of metastatic lesions is unpredictable. Although complete excision of metastases has been successful with good long-term survival, there have been several reports of long-term survival even with residual pulmonary tumors (Puri et al., 2007). The lesion most commonly affects the younger population, usually during the second and third decades of life. Pain is the most common symptom in GCTb because mechanical insufficiency resulting from bone destruction predisposes patients to fracture (Pereira et al., 2014). The distant metastasis and malignant transformation are extremely rare, include the lung, lymph nodes, liver, soft tissue, brain, mediastinum, scalp, kidney and penis (Muheremu and Niu, 2014). The frequency of pulmonary metastases in GCTb has ranged from $1 \%$ to $6 \% .29$ On histology, the lung metastases are identical to benign GCTb of bone. Dissemination appears to be hematogenous and could happen during curettage, but this remains unproved. It is difficult to predict the behavior of these metastatic benign lesions of the lungs. Spontaneous regression and disappearance have been reported. Progression is usually slow. Reports have suggested up to $70 \%$ survival following aggressive management of lung metastases with repeated surgery (Turcotte, 2006).

Bone tumors with metastases at diagnosis, have been associated with poor response to treatment (Li et al., 2014) and in a lower median survival, with approximately 30 months (Zuniga et al., 2005; Yang et al., 2012). Therefore, it is important to characterize metastasis according to different aspects involved in oncological pathology, therefore; the aim of this study was showed the association of metastasis with clinicopathological data in Mexican patients with OS, GCTb and CS during 2006 to 2014.

\section{Materials and Methods}

\section{Procedures}

We included 384 patients with clinical, radiological and histopathological diagnosis of OS, GCTb and CS that were attended at the National Rehabilitation Institute (INR) during 2006 to 2014. We reviewed clinical and pathological data was obtained taking into account ethical standards for consultation.

\section{Statistic analysis}

We calculated media and standard deviation, frequencies and percentages. Kolmogorov-Smirnov test, Chi square test, Fisher exact test and ANOVA were applied. Data analysis was performed using SPSS program v19. A confidence interval of $95 \%$ was considered.

\section{Results}

Data of 384 patients diagnosed with OS, GCTb and OS over a period of nine years were analyzed. $53.1 \%$ (204 cases) had a diagnosis of GCTb, 31.3\% (120 cases) was OS, and $15.6 \%$ (60 cases) was CS. The tumor type (OS, GCTb and CS) was significantly associated with the primary tumor localization ( $\mathrm{p}<0.05$ ); these results are shown in Table 1. The primary tumors were found most often in the lower and upper limbs in the three neoplasms. When the primary tumor was located in a limb, the right side was the most affected in the three tumor types $(\mathrm{OS}=57.5 \%, \mathrm{GCTb}=55.4 \%, \mathrm{CS}=53.3 \%$; $\mathrm{p}=0.93)$. Table 2 . show the frequencies of the anatomical sites affected with a primary tumor in relation to tumor type $(\mathrm{p}=0.0001)$. The femur was the most frequent for the OS, GCTb, and CS with 55\%, 29.4\% and $26.7 \%$ respectively. From the global perspective, in the $23.4 \%$ of the cases (90) metastases was diagnosed, of which $60 \%$ (54 cases) pulmonary location was found. A significant association between tumor type and presence of metastases $(\mathrm{p}=0.0001)$ with the location of the secondary tumor in the lung $(\mathrm{p}=0.0001)$ was

Table 1. Relationship of Tumor Type with the Primary Tumor

\begin{tabular}{lrrrr}
\hline & \multicolumn{4}{c}{ Frequencies } \\
\cline { 2 - 5 } Localization & OS & GCTb & CS & p value \\
\hline Upper Limb & $14.2 \%(17)$ & $27 \%(55)$ & $23.3 \%(14)$ & 0.001 \\
Lower Limb & $75.8 \%(91)$ & $67.2 \%(137)$ & $53.3 \%(32)$ & \\
Column & $4.2 \%(5)$ & $2 \%(4)$ & $6.7 \%(4)$ \\
Hip & $5.8 \%(7)$ & $3.8 \%(8)$ & $16.7 \%(10)$ \\
Total & $100 \%(120)$ & $100 \%(204)$ & $100 \%(60)$ & \\
\hline
\end{tabular}

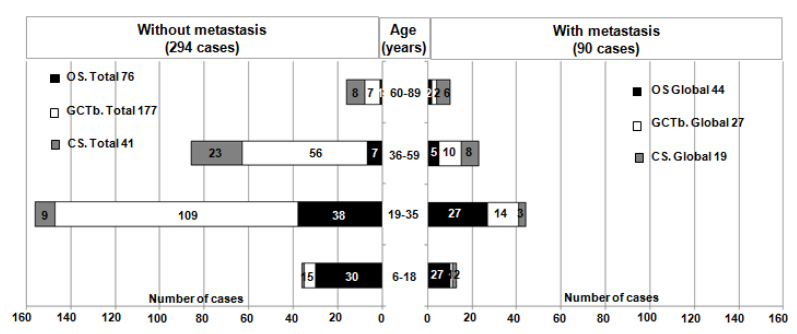

Figure 1. Relationship of Metastasis Cases by age Range and Type of Tumor 
Association of Metastasis with Clinicopathology in Mexican Cases of Osteosarcoma, Giant Cell Tumor and Chondrosarcoma

found; in the OS the frequency of metastases was $36.7 \%$ (44 cases) with $72.7 \%$ (32 cases) in lung; in GCTb was $13.2 \%$ (27 cases) with $51.8 \%$ (14 cases) in lung; whereas in the CS it was $31.7 \%$ (19 cases) with $42.1 \%$ (8 cases) in lung. In Table 3 can be seen that the year 2012 had the highest frequency of metastasis occurrence in three tumor types (global). The average age in relation to the discovery of metastases had no significant difference ( $\mathrm{p}>$ 0.05), however, patients with OS and GCTb accompanied by metastases had a higher average age, while CS was the inverse (without metastases: $O S=23 \pm 10.2$ years, $\mathrm{GCTb}=33.7 \pm 12.7$ years and $\mathrm{CS}=50.2 \pm 18.1$ years, with metastases: $\mathrm{OS}=26.6 \pm 12.5$ years, $\mathrm{GCTb}=36 \pm 16$ years, and $\mathrm{CS}=45.2 \pm 17.2$ years). In Figure 1, the age intervals are related to the presence or absence of metastasis with the tumor type. The male gender was most often related with global metastases with $56.7 \%(\mathrm{p}=0.06$ in relation to the three tumor types). For the OS, males had higher frequency of metastases $(68.2 \%, \mathrm{p}=0.09)$; in patients with $\mathrm{GCTb}$ and CS women had higher metastases frequency

Table 2. Global Frequencies by Type Tumor in Relationship to the Affected Anatomical Site

\begin{tabular}{|c|c|c|c|c|}
\hline & \multirow{2}{*}{$\frac{\text { Frequency }}{\text { Global }}$} & \multicolumn{3}{|c|}{ Frequency by type tumor } \\
\hline & & $\overline{\mathrm{OS}}$ & TCG & $\mathrm{CS}$ \\
\hline Anatomic site & $\mathrm{p}=0.0001$ & & $\mathrm{p}=0.0001$ & \\
\hline Humerus & $8.8 \%(34)$ & $10 \%(12)$ & $5.9 \%(12)$ & $16.6 \%(10)$ \\
\hline Femur & $37 \%(142)$ & $55 \%(66)$ & $29.4 \%(60)$ & $26.7 \%(16)$ \\
\hline Tibia & $19.3 \%(74)$ & $12.6 \%(15)$ & $24 \%(49)$ & $16.6 \%(10)$ \\
\hline Radius & $5.7 \%(22)$ & $3.3 \%(4)$ & $8.8 \%(18)$ & 0 \\
\hline Fibula & $3.4 \%(13)$ & $1.7 \%(2)$ & $4.9 \%(10)$ & $1.7 \%(1)$ \\
\hline Vertebra & $1.6 \%(6)$ & $0.8 \%$ & $2 \%(4)$ & $1.7 \%(1)$ \\
\hline Fingers & $1.3 \%(5)$ & 0 & $2.5 \%(5)$ & 0 \\
\hline Sacrum & $0.5 \%(2)$ & $0.8 \%(1)$ & $0.5 \%(1)$ & 0 \\
\hline Ulna & $2.1 \%(8)$ & $0.8 \%(1)$ & $3.4 \%(7)$ & 0 \\
\hline Calcanius & $0.8 \%(3)$ & 0 & $1 \%(2)$ & $1.7 \%(1)$ \\
\hline Hip & $5.2 \%(20)$ & $4.2 \%(5)$ & $2.9 \%(6)$ & $15 \%(9)$ \\
\hline Astragalus & $0.5 \%(2)$ & $0.8 \%(1)$ & 0 & $1.7 \%(1)$ \\
\hline Hand & $3.9 \%(15)$ & 0 & $5.9 \%(12)$ & $5 \%(3)$ \\
\hline Scapula & $1.6 \%(6)$ & $2.5 \%(3)$ & 0 & $5 \%(3)$ \\
\hline Foot & $2.3 \%(9)$ & $1.7 \%(2)$ & $2.9 \%(6)$ & $1.7 \%(1)$ \\
\hline Knee & $4.4 \%(17)$ & $4.2 \%(5)$ & $4.9 \%(10)$ & $3.2 \%(2)$ \\
\hline Olecranon & $0.5 \%(2)$ & 0 & $0.5 \%$ & $1.7 \%$ (1) \\
\hline Clavicle & $0.3 \%(1)$ & $0.8 \%$ & 0 & 0 \\
\hline Iliac & $0.8 \%(3)$ & $0.8 \%(1)$ & $0.5 \%$ & $1.7 \%(1)$ \\
\hline Total & $100 \%(384)$ & $100 \%(120)$ & $100 \%(204)$ & $100 \%(60)$ \\
\hline
\end{tabular}

Table 3. Anatomical Site Relationship with the Presence of Metastases at Diagnosis

\begin{tabular}{|c|c|c|c|c|}
\hline \multirow[t]{3}{*}{ Anatomical site } & \multicolumn{4}{|c|}{ Metastases frequency } \\
\hline & Global & OS & $\mathrm{TCG}$ & $\mathrm{CS}$ \\
\hline & $\mathrm{p}=0.13$ & $\mathrm{p}=0.45$ & $\mathrm{p}=0.73$ & $\mathrm{p}=0.34$ \\
\hline Humerus & $10 \%(9)$ & $6.8 \%(3)$ & $7.4 \%(2)$ & $21.1 \%(4)$ \\
\hline Femur & $44.4 \%(40)$ & $54.5 \%(24)$ & $44.4 \%(12)$ & $21.1 \%$ \\
\hline Tibia & $15.6 \%(14)$ & $20.5 \%(9)$ & $14.8 \%(4)$ & $5.3 \%(1)$ \\
\hline Radius & $1.1 \%(1)$ & $2.3 \%(1)$ & 0 & 0 \\
\hline Fibula & $1.1 \%(1)$ & 0 & $3.7 \%(1)$ & 0 \\
\hline Vertebra & $1.1 \%(1)$ & 0 & $3.7 \%(1)$ & 0 \\
\hline Fingers & 0 & 0 & 0 & 0 \\
\hline Sacrum & 0 & 0 & 0 & 0 \\
\hline Ulna & $1.1 \%(1)$ & 0 & $3.7 \%(1)$ & 0 \\
\hline Calcanius & 0 & 0 & 0 & 0 \\
\hline Hip & $8.9 \%(8)$ & $2.3 \%(1)$ & $7.4 \%(2)$ & $26.3 \%(5)$ \\
\hline Astragalus & $1.1 \%(1)$ & $2.3 \%(1)$ & 0 & 0 \\
\hline Hand & $3.3 \%(3)$ & 0 & $3.7 \%(1)$ & $10.5 \%(2)$ \\
\hline Scapula & $3.3 \%(3)$ & $4.5 \%(2)$ & 0 & $5.3 \%(1)$ \\
\hline Foot & $3.3 \%(3)$ & $2.3 \%(1)$ & $3.7 \%(1)$ & $5.3 \%(1)$ \\
\hline Knee & $3.3 \%(3)$ & $2.3 \%(1)$ & $7.4 \%(2)$ & 0 \\
\hline Olecranon & $1.1 \%(1)$ & 0 & 0 & $5.3 \%(1)$ \\
\hline Clavicle & $1.1 \%(1)$ & $2.3 \%(1)$ & 0 & 0 \\
\hline Iliac & 0 & 0 & 0 & 0 \\
\hline Total & $100 \%(90)$ & $100 \%(44)$ & $100 \%(27)$ & $100 \%(19)$ \\
\hline
\end{tabular}


Table 4. Metastasis Frequency at Diagnosis and Relationship to Type Tumor

\begin{tabular}{lrrrr}
\hline & \multicolumn{4}{c}{ Metastasis frequency } \\
\cline { 2 - 5 } Ylobal & \multicolumn{1}{c}{ OS } & GCTb & \multicolumn{1}{c}{ CS } \\
\hline Year & $\mathrm{p}=0.0001$ & & $\mathrm{p}=0.32$ \\
2006 & $7.8 \%(7)$ & $13.6 \%(6)$ & $3.7 \%(1)$ & \multicolumn{1}{l}{0} \\
2007 & $8.9 \%(8)$ & $6.8 \%(3)$ & $18.5 \%(5)$ & 0 \\
2008 & $8.9 \%(8)$ & $15.9 \%(7)$ & 0 & $5.3 \%(1)$ \\
2009 & $16.7 \%(15)$ & $13.6 \%(6)$ & $18.5 \%(5)$ & $21.1 \%(4)$ \\
2010 & $4.4 \%(4)$ & $4.5 \%(2)$ & $3.7 \%(1)$ & $5.3 \%(1)$ \\
2011 & $8.9 \%(8)$ & $6.8 \%(3)$ & $11.1 \%(3)$ & $10.5 \%(2)$ \\
2012 & $20 \%(18)$ & $18.2 \%(8)$ & $22.2 \%(6)$ & $21.1 \%(4)$ \\
2013 & $14.4 \%(13)$ & $9.2 \%(4)$ & $14.8 \%(4)$ & $26.3 \%(5)$ \\
2014 & $10 \%(9)$ & $11.4 \%(5)$ & $7.4 \%(2)$ & $10.5 \%(2)$ \\
\hline Total & $100 \%(90)$ & $100 \%(44)$ & $100 \%(27)$ & $100 \%(19)$ \\
\hline
\end{tabular}

with $51.9 \%(\mathrm{p}=0.44)$ and $57.9 \%(\mathrm{p}=0.56)$ respectively. With respect to the laterality of the primary tumor and its relationship to metastasis, the right $(\mathrm{R})$ side occurred more frequently with $54.4 \%$, and the left (L) side with $43.3 \%$; finally without laterality (WL=involvement no limbs sites) $2.2 \%(\mathrm{p}=0.9)$. The metastases laterality by type tumor, was more frequent in the right side to OS $(\mathrm{D}=63.6 \%, \mathrm{I}=36.4 \%$, $\mathrm{SL}=0, \mathrm{p}=0.3)$ and $\mathrm{GCTb}(\mathrm{D}=55.6 \%, \mathrm{I}=40.7 \% \mathrm{SL}=3.7 \%$, $\mathrm{p}=0.9$ ), while for the CS was more frequent on the left side ( $\mathrm{I}=63.2 \%, \mathrm{D}=31.6 \%, \mathrm{SL}=5.3 \%, \mathrm{p}=0.07)$. The location of the primary tumor from a general view, had the following frequencies associated with the presence of metastases: In the upper limb (UL) was $17.4 \%$, in lower limb (LL) of $23.8 \%$, in the column was $38.5 \%$, and in the hip $32 \%$ $(\mathrm{p}=0.22)$. Analyzing this location-metastasis stratified relationship by type of tumor, we found that for the OS was higher this association when the primary tumor was in $\mathrm{LL}=81.8 \%$ (36 cases). For GCTb, was $74.1 \%$ in LL, whereas in the CS was $36.8 \%$ in UL. Table 4 shows the relationship between the anatomical site and the presence of metastases. Globally, metastasis was associated with a primary tumor in femur $(44.4 \%)$, followed by the tibia $(15.6 \%)$; in OS and GCTb this association was more frequent in the same bones, but for CS the hip had the first location with $26.3 \%$.

\section{Discussion}

It has been shown in several studies that the discovery of metastases at diagnosis, is an important factor determining the survival of patients with bone neoplasms (Garza et al., 1999; Zuniga et al., 2005; Yang et al., 2012; Choeprasert et al., 2014; Joo et al., 2015; Muscolo et al., 2015) and this behavior has been associated with various features such as high malignancy (Garza et al., 1999; Yang et al., 2012; Linares-Gonzalez et al., 2014; Joo et al., 2015), local recurrence, (Niu et al., 2012; Li et al., 2015) genetic and hormonal stimuli (Niu et al., 2014; Uribe-Rosales et al., 2014), unconventional age and the anatomical region of the primary tumor (Uribe-Rosales et al., 2014; Joo et al., 2015), history of pathologic fracture due to the primary tumor (Cortes-Rodriguez et al., 2010), no chemotherapy or improper surgical handling (Muscolo et al., 2009) and tumor size (Weber et al., 2002; Yang et al., 2012). In our study, in 2012, increased frequency of metastases at diagnosis was observed; however, to discuss this aspect, we need to collect information on the methods applied for detection of metastases.

OS has been classified in metastatic and non-metastatic tumor due to the high frequency of this condition at diagnosis (Niu et al., 2014). Previous studies have reported a frequency of metastases in a range of $15 \%$ in the US to 60\% in Thailand (Zhu et al., 2013; Choeyprasert et al., 2014). In this study, we observed a metastases frequency of $36.7 \%$, this result is within the range reported in other countries, and is similar to the $36 \%$ mentioned by ZunigaNiembro at the Instituto Nacional de Pediatria in Mexico City in the period of 19911998 (Zuniga et al., 2005). It is important to mention that the lung is where the discovery of metastasis is more common (31\% to $80 \%$ ), this is similar with the $72.7 \%$ observed in our study (Ferguson et al., 2001; Zuniga et al., 2005; Muscolo et al., 2009; Choeyprasert et al., 2014). In relation to gender, men presented higher metastases frequency (Ries et al., 1999; Muscolo et al., 2009). In our study, all OS cases between ages 6 to 70 were included; note that the higher frequency of metastases was found in the age range of 19-35 years $(61.4 \%)$, this could be because the range of 19-25 years (40.9\%) concentrated the increased frequency of OS. Primary tumors in the femur and tibia, were associated with higher frequency of metastasis, this is similar with previously reports (Uribe-Rosales et al., 2014).

Regarding GCTb has been reported metastasis of 1 to $29 \%$ depending on the radiological Enneking classification (Present, 1986; Garza et al., 1999; Niu et al., 2012). This study is limited because tumor staging and histopathological features are not included. The metastases are considered to be benign and bear the same histological characteristics of the original tumor (Raksin et al., 2013). Although this type of tumor is predominant in women, metastasis are more frequent in men (Arnold et al., 2011; Llamas-Duran et al., 2011; Sanchez-Torres et al., 2012). Most patients ranged from 26 to 35 years had higher metastases frequency $(40.7 \%)$, this age range is similar to that reported in the literature as peak incidence (Garza et al., 1999; Arnold et al., 2011; Niu et al., 2012; Sanchez-Torres et al., 2012). The primary tumor laterality associated with metastases were the right side as in the OS. Also, the primary tumor located in long bones of the lower limb (femur) was the most associated to metastases; this may be because this anatomical site is the most common site were the GCTb appears as a primary neoplasm (Arnold et al., 2011; Llamas-Duran et al., 2011; Niu et al., 2012; Sanchez-Torres et al., 2012).

CS in our population was $31.7 \%$ of metastasis frequency, of which $51.8 \%$ went to the lung, it exceeds that reported in the literature, where frequencies ranging around $10 \%$, of which $37 \%$ was lung (Chow, 2007; Yang et al., 2012) and differs from that mentioned by Gelderblom, et al, 2008, for having low metastasis probability. We observed that patients with metastases had an average age 5 years younger than patients without metastases. Patients aged 47-59 years had more often the CS as primary tumor; however, three peaks with higher percentage of metastases were seen in ages of 12 to 18,36 to 46 years and 60 to 
Association of Metastasis with Clinicopathology in Mexican Cases of Osteosarcoma, Giant Cell Tumor and Chondrosarcoma

70 years. In this study the presence of metastasis was more frequent in women; this is similar with the overall frequency of CS as the primary tumor. It is interesting to analyze that women had a higher frequency of the primary tumor in the femur, while men in hip; however; were not men who had higher percentage of metastases as expected. Added to this, the primary tumor on the left side was the one who was associated with increased metastasis and its location in upper extremity and hip $(\mathrm{p}=0.09)$.

In conclusion, the finding of metastases in the OS, $\mathrm{GCTb}$, and CS is determined by age, gender, anatomical location, surgical, radiological and medical treatment as well as aspects inherent to the pathophysiology of tumor and time of evolution. Studies have shown that the discovery of metastases at diagnosis of OS, GCTb and CS is associated with lower survival, therefore, it is important to rule out metastases and micro-metastases from the first contact with the patient, not only with radiography thorax, but also use the Computed Tomography (CT), magnetic resonance imaging to rule saltatory metastasis, bone gammagram, positron emission tomography (PET Scan), the imaging integrated PET/CT and whole-body bone scan to evaluate multiple bone injuries and direct palpation during metastatic resection surgery and determination of Lactic Dehydrogenase. In reality, it is difficult to practice in the same patient all the aforementioned studies, especially in countries where the population has economic hardship and difficulty to access to comprehensive health services, such as ours; however, it would be advisable to study individual diagnostic test and in parallel to each of them, relate to sensitivity and specificity with clinicopathological factors and thus limit the most appropriate management to rule out metastasis, micrometastases and saltatory metastasis in patients with bone neoplasms.

\section{References}

Arnold RT, van Holsbeeck MT, Mayer TG, Mott MP, Koch SR (2011). Necrotic giant cell tumor of bone manifesting with pathologic fracture. Radio Graphics, 31, 93-8.

Azarpira N, Javadi F, Safarian A (2015). Giant cell tumor of the thoracic vertebra: a case report. Neurosurg $Q, 25,264-6$.

Baena-Ocampo L del C, Ramirez-Perez E, Linares-Gonzalez LM, Delgado-Chavez R (2009). Epidemiology of bone tumors in Mexico City: retrospective clinicopathologic study of 566 patients at a referral institution. Ann Diagn Pathol, 13, 16-21.

Choeyprasert W, Pakakasama S, Sirachainan N, et al (2014). Comparative outcome of Thai pediatric osteosarcoma treated with two protocols: the role of high-dose methotrexate (HDMTX) in a single institute experience. Asian Pac J Cancer Prev, 15, 9823-9.

Chow WA (2007). Update on chondrosarcomas. Curr Opin Oncol, 19, 371-6.

Cintra FF, Etchebehere M, Goncalves JC, Cassone AE, Amstalden EM (2014). Vascular pattern in enchondroma and chondrosarcoma: clinical and immunohistologic study. Appl Immunohistochem Mol Morphol, 22, 600-5.

Cortes-Rodriguez R, Castaneda-Pichardo G, Tercero-Quintanilla $\mathrm{G}$ (2010). Guia de diagnostico y tratamiento para pacientes pediatricos con osteosarcoma. Inv Mat Inf, 2, 60-6.

De la Garza NJM, Ceccopieri CA, Cruz Ortiz H, Diaz Rodriguez LR, Martinez Macias R (1999) Tumor de celulas gigantes de hueso. Aspectos generales de 11 casos. Rev Med Hosp Gen Mex, 62, 240-4.

Ferguson WS, Goorin AM (2001). Current treatment of osteosarcoma. Cancer Invest, 19, 292.

Gelderblom H, Hogendoorn PC, Dijkstra SD, et al (2008). The clinical approach towards chondrosarcoma. Oncologist, 13, 320-9.

Huang YJ, He AN, Sun YJ, et al (2015). Continuous-infusion ifosfamide and doxorubicin combination as second-line chemotherapy for recurrent or refractory osteosarcoma patients in China: a retrospective study. Asian Pac J Cancer Prev, 16, 2391-5.

Joo MW, Shin SH, Kang YK, et al (2015). Osteosarcoma in asian populations over the age of 40 years: a multicenter study. Ann Surg Oncol, 13.

Li YY, Jiang XM, Dong YG, Xu G, Ma YB (2014). Ifosfamidecontaining regimens for treating patients with osteosarcomas. Asian Pac J Cancer Prev, 15, 9763-6.

Linares-Gonzalez M, Rico Martinez G, Dominguez-Herandez VM, et al (2014). Tratamiento y reconstruccion en tumores oseos del humero con protesis no convencional tipo RIMAG. Acta Ortop Mex, 28, 3-11.

Liu X, Min L, Chen G, Hong S, Tu C (2015). Bony metastases following complete resection of periosteal chondrosarcoma. World J Surg Oncol, 13, 121.

Llamas-Duran LF, Tarango-Martinez VM, Fuentes-Sermeno IL, Fajardo-Barajas D (2011). Tumor de Celulas Gigantes del hueso de localizacion infrecuente. Med Cutan Iber Lat Am, 39, 234-7.

Martinez-Cedillo J (2012). Osteosarcoma. Success of adjuvant chemotherapy. After 25 years. Is there something new? GAMO, 11, 293-5.

Muheremu A, Niu X (2014). Pulmonary metastasis of giant cells tumor of bones. World J Surg Oncol, 12, 261.

Murphey MD, Nomikos GC, Flemming DJ, et al (2001). From the archives of AFIP. imaging of giant cell tumor and giant cell reparative granuloma of bone: radiologic-pathologic correlation. Radiographics, 21, 1283-309.

Muscolo DL, Farfalli G, Aponte-Tinao LA, Ayersa MA (2009). Actualizacion en osteosarcoma. Rev Asoc Argent Ortop Traumatol, 74, 85-1.

Niembro Zuniga AM, Castellanos Toledo A, Gutierrez Castrellon $\mathrm{P}$, et al (2005). Resultados de ocho anos en el tratamiento de Osteosarcoma. experiencia en el instituto nacional de pediatria, mexico. Gamo, 4, 34-0.

Niu X, Zhang Q, Hao L, et al (2012) Giant cell tumor of the extremity: retrospective analysis of 621 Chinese patients from one institution. J Bone Joint Surg Am, 94, 461-7.

Niu F, Zhao S, Xu CY, et al (2014). Identification and functional analysis of differentially expressed genes related to metastatic Osteosarcoma. Asian Pac J Cancer Prev, 15, 10797-1.

Pereira HM, Marchiori E, Severo A (2014). Magnetic resonance imaging aspects of giant-cell tumours of bone. J Med Imaging Radiat Oncol, 58, 674-8.

Picci P (2007). Osteosarcoma (osteogenic sarcoma). Orphanet J Rare Diseases, 2, 6.

Present D, Bertoni F, Hudson T, Enneking WF (1986). The correlation between the radiologic staging studies and histopathologic findings in aggressive stage 3 giant cell tumor of bone. Cancer, 57, 237-4.

Puri A, Agarwal MG, Shah M, et al (2007). Giant cell tumor of bone in children and adolescents. J Pediatr Orthop, 27, 635-9.

Raskin KA, Schwab JH, Mankin HJ, Springfield DS, Hornicek FJ (2013). Giant cell tumor of bone. J Am Acad Orthop Surg, 21, 118-6. 


\section{E Estrada-Villaseñor et al}

Ries LA, Smith MA, Gurney JG, et al (1999). Cancer incidence and survival among children and adolescents: united states seer program 1975-1995, national cancer institute, SEER program. NIH Pub. Bethesda, MD. 99-9.

Sanchez-Torres LJ, Flores Flores A, Santos Hernandez M (2012). Tumor oseo de celulas gigantes en pacientes de menos de 20 anos de edad. Rev Mex Ortop Ped, 14, 26-0.

Turcotte RE (2006). Giant cell tumor of bone. Orthop Clin North Am, 37, 35-1.

Uribe-Rosales D, Carranza-Arellano C, Ramos-Moreno R (2014). Aspectos biologicos y clinicos para comprender mejor al osteosarcoma. Inv Disc, 3, 33-0.

Weber KL, Pring ME, Sim FH (2002). Treatment and outcome of recurrent pelvic chondrosarcoma. Clin Orthop Relat Res, 397, 19-8.

Yang ZM, Tao HM, Ye ZM, et al (2012). Multivariate analysis of the prognosis of 37 chondrosarcoma patients. Asian Pac J Cancer Prev, 13, 1171-6.

Zhu L, McManus MM, Hughes DP (2013). Understanding the biology of bone sarcoma from early initiating events through late events in metastasis and disease progression. Front Oncol, 17, 1-17. 